\title{
Analysis on Costumers of Red APP
}

\author{
Man Shuya ${ }^{1}$ \\ ${ }^{1}$ Suzhou Experimental High School, Jiangsu Province, Suzhou China
}

\begin{abstract}
With the popularization and development of the Internet, the Internet has become the daily needs of people. Life shopping software, as a network accessory, is becoming an important part of people's lives. The reason why Red APP is so successful, in addition to the advantages of the product itself, its customer pertinence is also inseparable. Red APP delivers its products to the audience through its unique and cordial operation method, allowing audiences to share their lives with each other and resonate, to feel the sense of participation and the joy of pursuing a refined life. The article first interprets the indicators of Red APP, and then analyzes the characteristics of its users from different perspectives.
\end{abstract}

\section{INTRODUCTION}

In 2013, "Red APP" took advantage of the trend. This close-to-life software quickly entered the public eyes after it was launched, and Red APP has been recognized by users and industry professionals. Unlike other e-commerce platforms, Red APP started from the community. At the beginning, users focused on sharing overseas shopping experience in the community. Later, in addition to beauty and personal care, Red APP appeared on sports, tourism, home, travel, hotels, and restaurants, which touched on the consumption experience and all aspects of lifestyles.

At the end of 2014, Red APP 's "Welfare Agency" went online, started the e-commerce business, and completed the commercial closed loop. From the community to the e-commerce, the real promoter of Red APP is users. Many users feedback that they are unwilling to accept the experience of being "planted" but unable to "pull the grass". Communities, cross-border e-commerce, sharing platforms, and word-of-mouth libraries etc. [1]In the end, the number of Red APP users currently exceeds 70 million, with about 200,000 new users every day. And its e-commerce exceeds 10 billion. In just 5 years, a must-have "shopping artifact" for more than 70 million young people in more than 200 countries, has become the world's largest consumer reputation database and community e-commerce platform.

\section{Customer eXPerienCes.}

Red APP cancels the promotion of merchants and relies on the "consumption notes" written by users' word-of-mouth, which not only introduces the products in a more authentic way, but also delivers a new and beautiful way of life. Red is the most differentiated from other cross-border e-commerce businesses. Users are encouraged to share and exchange their feelings about the goods. Buying goods, especially buying cosmetics, a big pain point is not to know the goods is good or bad, whether suitable for their own. Sometimes users want to read other people's comments, but they don't know where to look. Although other shopping apps and e-commerce enterprises have evaluation systems, the evaluations are all short reviews and it is difficult to know the actual use situation. [1]Although Koala.com encourages long-term reviews in evaluation, the transaction volume is still small, and there is no place for evaluation of a large number of products. Other review websites, Douban and Weibo are full of writers and mercenaries, so it is difficult to find real comments. However, Red APP takes the note system as its core function. Users will easily have a sense of trust and dependence when they see a large number of comments generated by other users, all of which are detailed reviews, thus increasing their trust in the commodities sold on the platform. Users can see the products that meet the requirements in their mind in the notes, directly buy them through Red, and then write down their feelings in Red after the purchase, finally forming a closed loop of experience.

Red APP provides customers with a variety of interactive methods: comment, favorite, follow and share. Unlike other social software such as Facebook and Weibo, the content of Red APP focuses on life, allowing users to share their own lives in the form of notes while feeling the lives of others. A note with pictures is fun and quick to read. The best feature of Red APP -collection functionis also very humane. Customers can classify the collected notes into gourmet recipes, tourist attractions, shopping guides, etc, facilitating later viewing and reading. In this way, Red APP has become a practical tool for users to record a good life.

Corresponding author: manshuya87@163.com 


\section{TARGET CUSTOMERS}

Red's target customers are positioned as young women with medium to high spending power. At the same time, the income level of this group of people makes their spending power and willingness extremely high. The target market is the sales field of overseas mid-to-high-end women products. The market is segmented and there are fewer competitors. This is necessary for start-up products and companies. From traditional business to the current Internet industry, women are recognized as trend leaders. Their instincts to "go around" and shopping coupled with the economic conditions brought about by income make them have higher spending power. Therefore, the main customers of Red APP are young female white-collar workers or students in first-tier cities, which can be said to be an efficient combination of economic strength and consumer willingness. At the same time, customers with obvious characteristics have brought community discussions that are more focused on female topics such as skin care, beauty, bags, and health products. While discussions on digital and outdoor products are relatively unpopular, which also makes Red overlap in some customers. It enjoys a certain degree of popularity in high fashion and tourism circles. Among these customers, girls are the main power because they like to expose clothes, to improve their knowledge of fashion and shopping Gender Distribution w/o Undefined

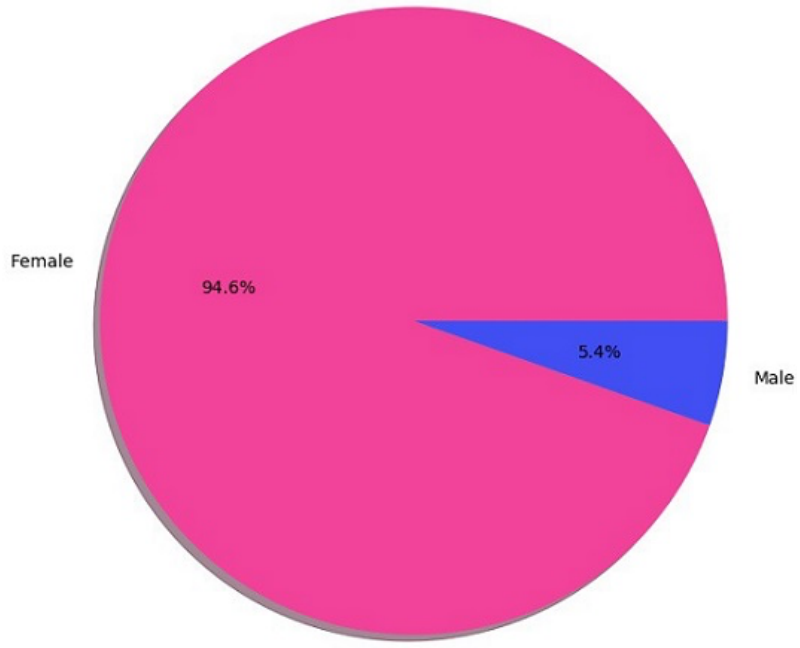

standards, and to record the beauty of life through showing beauties. Therefore, positioning young mid-to-high-end women consumers as the main consumer users can attract more people's attention by using high-quality social interaction. Moreover, the essence of Red is to make a lifestyle,which is a good starting point that attracted many young female consumers.

\section{USE PIE CHARTS FOR ANALYSIS}

\subsection{Gender Distribution}

In order to analyze the differentiation of the users between female and male, pie charts are made to compare the distribution in gender.The chart above shows the occupation of customers in different genders in 2019. The left chart shows that only $2 \%$ of them are men, $33.9 \%$ are women, and the remaining more than $60 \%$ of users have no certified gender. In order to compare the occupation of female and male, the right chart clearly demonstrate the result by excluding customers whose gender is not indicated. In the chart, women account for $95 \%$ of the total number of customers. This is similar to our expectation because most of the content on Red is aimed at women, including various beauty products and fashion-related content.

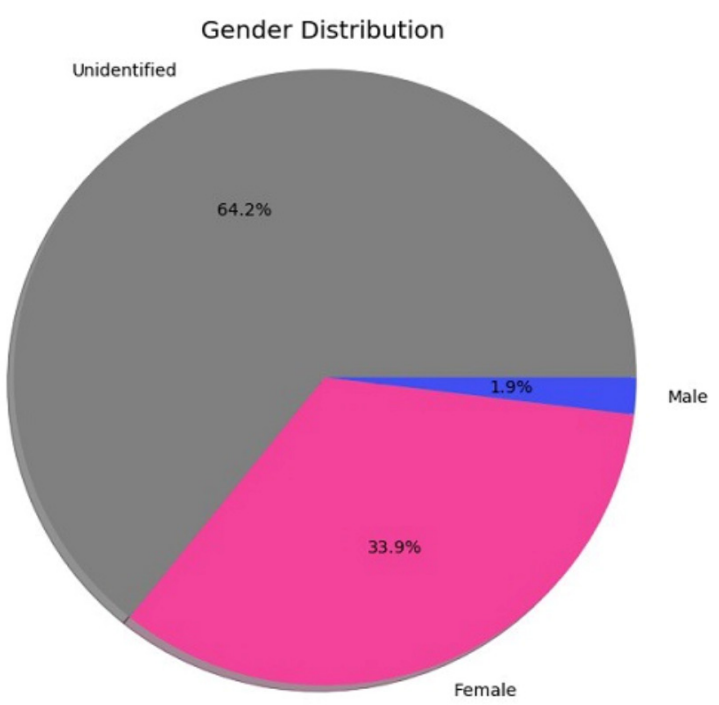

Figure 1. Occupation of customers in different genders[2]

From the chart, it is clear to see that Red APP focus on the female costumers is a good choice. Red APP targets the costumers to women. Unlike other shopping apps which only focus on selling products, Red APP made a good decision at the beginning.

\section{2 "Favorite and like" Ratio Distribution}

Although male users only account for $5 \%$ of the total number of users in Red, their influence cannot be underestimated. The two pie charts bellow both demonstrate the fraction of two genders. The different is the category. The left chart is the fraction about collected notes, otherwise, the right chart shows sum of likes generated by each gender. After separately counting the content posted by male and female veterans, it is easy to found that the content of male veterans was "liked" accounting for $8 \%$ of the total;

At the same time, the number of "favorites" of male big V (users who have obtained personal authentication and have many fans) content accounted for $5.9 \%$ of the total, which is slightly lower than the percentage of "likes" but still higher than the percentage of their gender. The explanation for this gap is that the content posted by the male $\mathrm{V}$ in Red is very interesting, but readers don't necessarily want to read it again later. On the other hand, the content released by female big $\mathrm{V}$ is worth reading more later. 


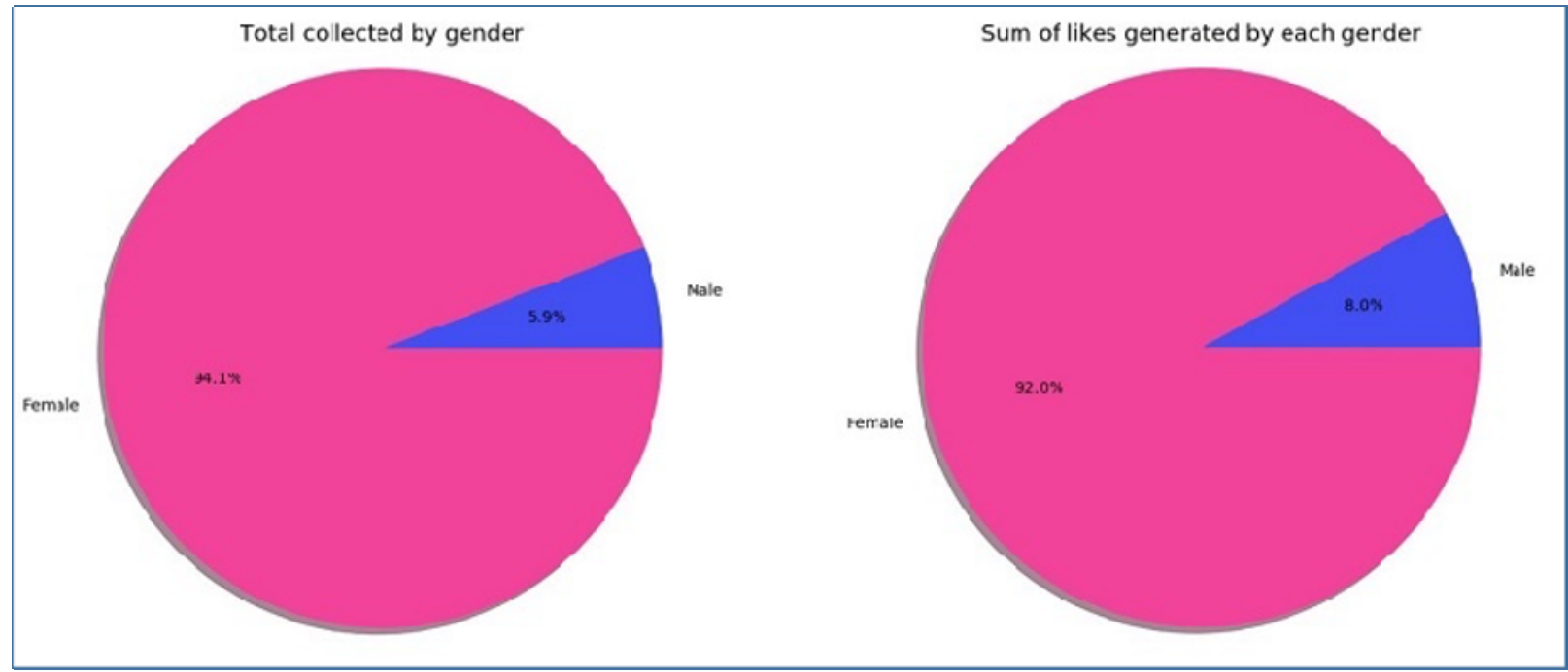

Figure 2. Occupation of "Favorite and like" ratio in different genders[3]

\subsection{Fans Numbers Distribution.}

In order to prove this finding, the influence of users is also an indispensable way of analysis, which can be well reflected in the proportion of fans. Generally speaking, female users who post more useful content should be more influential than male users. However, judging from the proportion of their respective fans, the result is completely opposite. This pie chart shows the percentage of users' followers. From the scope of influence, male users have greater influence. Male users have a higher number of fans on average comparing to the gender distribution. Specific statistics are reliable.

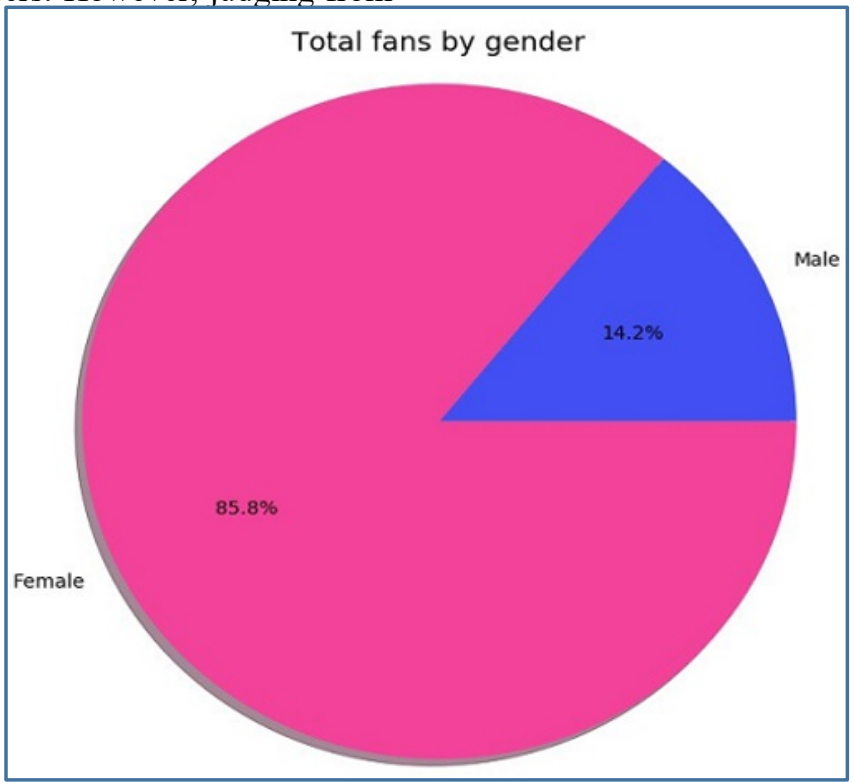

Figure 3. Occupation of total fans in different genders. [4]

\subsection{Sample Characteristics of Genders}

Interestingly, the median and quartile analysis showed opposite results. The median of male users' fans is 5, while the median of female users is 11 . The quartile results also show that the coverage of most male fans is lower than that of females.

\begin{tabular}{|rrrrrrrrr}
\hline & count & mean & std & min & $\mathbf{2 5 \%}$ & $\mathbf{5 0 \%}$ & $\mathbf{7 5 \%}$ & $\max$ \\
gender & & & & & & & & \\
\hline $\mathbf{0}$ & 17402.0 & 2443.376623 & 54614.411730 & 0.0 & 1.0 & 5.0 & 17.0 & 5067245.0 \\
1 & 304567.0 & 842.971822 & 33001.537039 & 0.0 & 4.0 & 11.0 & 33.0 & 10384581.0 \\
\hline
\end{tabular}

Figure 4. Sample Characteristics of genders[5] 


\section{Celebrity Influence}

Although in a sense, the average personal influence of male users is greater than that of female users. However, Red is more important than female users, and female users drive the operation of this software. Red's company is very good at using this. Nowadays, the presence of celebrities in Red is also a highlight of this software. Incoming stars will interact with fans by posting personal notes. In order to allow celebrities to enter this way to create a more comprehensive influence, both male and female celebrities have entered. But the influence of female celebrities is great, because they also love to share beautiful things like most users.

An obvious trend is that the development of the Internet allows artists to get rid of professional mystery. The new Internet community platform represented by Red allows artists to lose their role and return to the status of ordinary people.

For the celebrity list launched by Red this time, the interaction rate is the core indicator to measure the influence of celebrities, and it also proposes a new measurement index for the influence of celebrities. In the past, the outside world's judgment on the influence of celebrities mainly depended on the volume of media. In Red, it is more accurate to use "the power of real life" to describe the influence of a star.

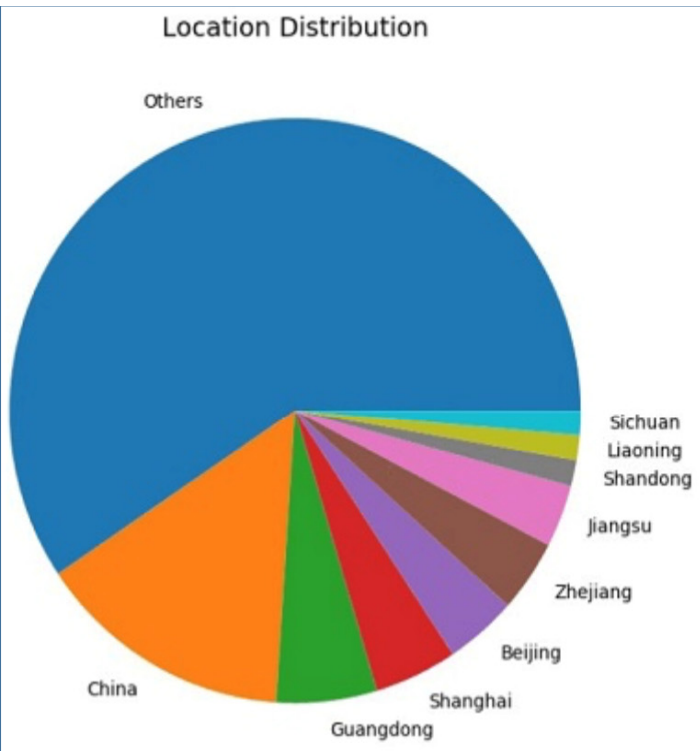

\section{Geographical Distribution of Users}

Red is known for its high sales conversion rate. Users on the platform are often interested in buying high-end beauty and fashion products. Many people refer to Red as a "grass planting platform", which basically means that people search for products they are interested in and ultimately stimulate their desire to buy.

Most of the products mentioned in Red are international brands, so users usually have high purchasing power. So where are these users distributed? Most high-income groups are mainly located in Beijing, Shanghai, Shenzhen and Guangdong. Does the user base fit this demographic?

Analyze the data of the user's location is a good choice. Since Red defaults the user's location to "Other", we see that only $40 \%$ of users enter meaningful location information. At the same time, the location information entered by some users is not specific. In this article, for the purpose of analysis, focusing on those users whose provincial and municipal locations are indicated is excellent.

The top five provinces and cities for users are Guangdong, Shanghai, Beijing, Zhejiang and Jiangsu, which account for more than $30 \%$ of the entire user base. Xiaohongshu is headquartered in Shanghai, which explains why Shanghai is its main user base. Guangdong Province has the highest proportion of total GDP, and it also includes the two major cities of Guangzhou and Shenzhen, so it is not surprising that Guangdong Province has a large number of users.

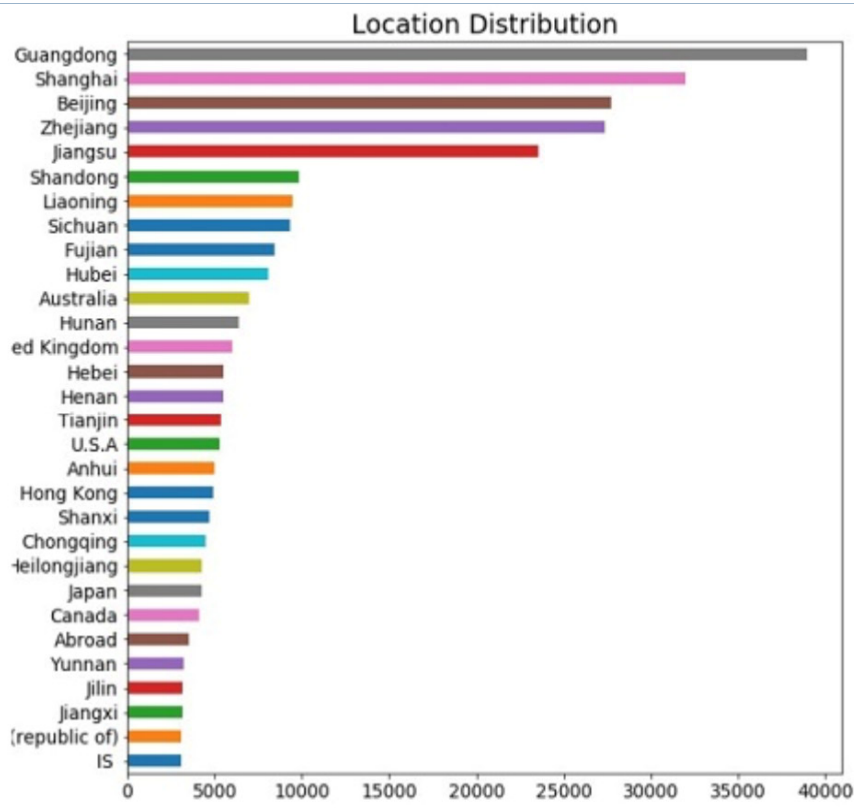

Figure 5. Location distribution of users[6] 


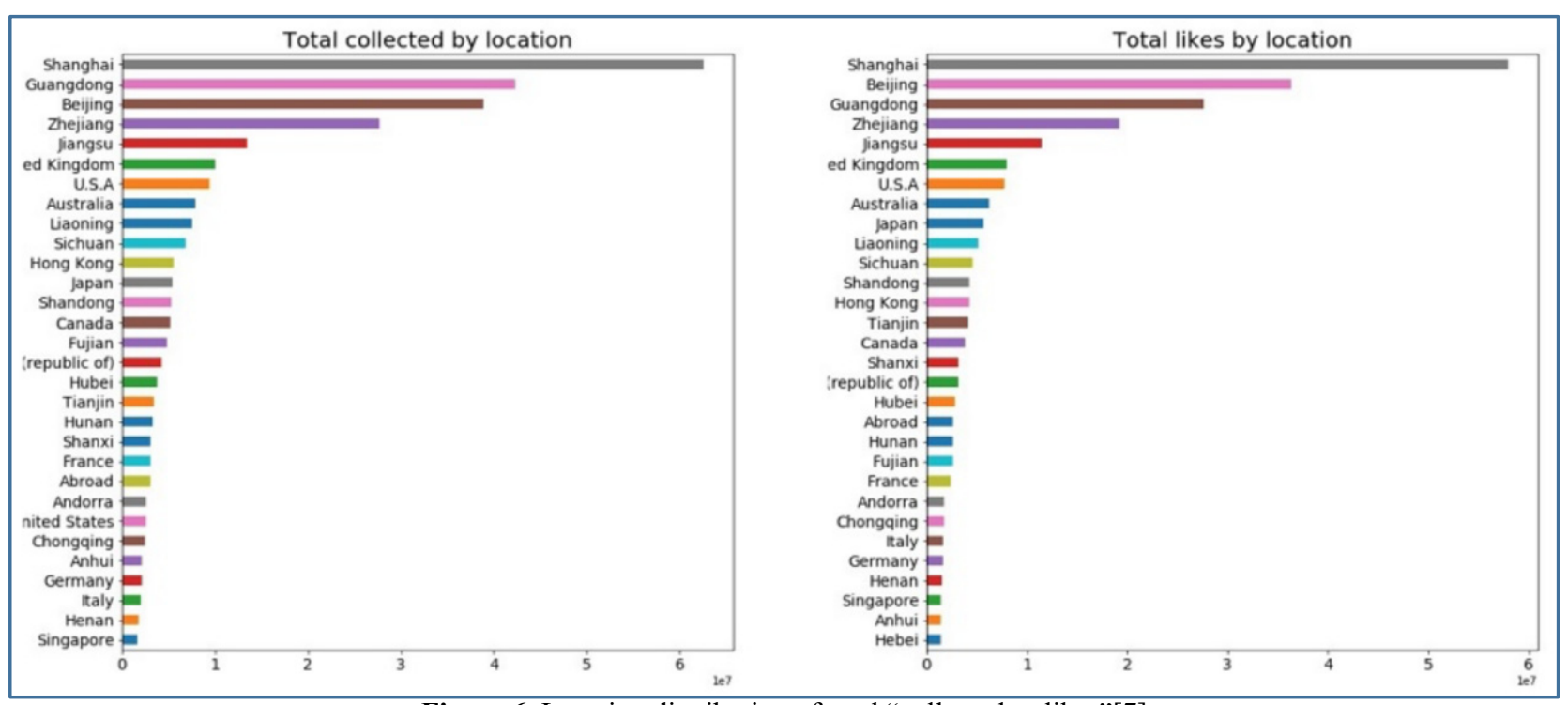

Figure 6. Location distribution of total "collected or likes"[7]

Although the quantitative distribution shows that Guangdong Province has the most users, when analyzing the geographical distribution of users, the quality of users, that is, the degree of user participation must also be considered. In terms of "Like" and "Collection", Shanghai leads the way.

Another interesting trend is that some influential big $\mathrm{Vs}$ in Xiaohongshu live overseas. Among them are mainly located in countries such as Australia, the United States and the United Kingdom. Compared with the big V in China, there are more fans of the big $\mathrm{V}$ overseas. Although the quantitative distribution shows that Guangdong Province has the most users, when analyzing the geographical distribution of users, the quality of users, that is, the degree of user participation must also be considered.In terms of "Like" and "Collection", Shanghai leads the way.

Another interesting trend is that some influential big Vs in Red live overseas. Among them are mainly located in countries such as Australia, the United States and the United Kingdom. Compared with the big V in China, there are more fans of the big $\mathrm{V}$ overseas.

\section{ConCLuSION}

The main users of Red are women, and less than $20 \%$ of male users. In the future, Red can continue to attract new users. In addition to women, male users are also a key point to be explored, and the content of the platform is biased towards female users. There are many, so in the future, the needs and value of male users can be explored more deeply. In addition to e-commerce and advertising, Red is also exploring new monetization models. In view of the fact that there are many travel and shop search content on the platform that are widely favored by users, localized services may be a direction for Red to monetize.

At the same time, the users of Red are mainly concentrated in first- and second-tier cities, so when further user growth is done, it is important to consider sinking the market and expand in third- and fourth-tier cities and below.

\section{ACKNOWLEDGMENT}

This research was supported by Martin Liu, Cucumber Media. Thanks for my teacher Mr Barbee and Mr Patrick. Thanks for Red App gives me the chance to do the statistic analysis.

\section{REFERENCES}

1. Chu Jiali and Li Zying. Analysis of Marketing Skills -- A Case Study of "Little Red Book" APP [J]. Taxation,2018(11):137-138.

2. Martin Liu. Occupation of customers in different genders. Cucumber Media. 2018, Oct 18. http://www.opp2.com/102749.html

3. Martin Liu. Occupation of "Favorite and like" ratio in different genders. Cucumber Media. 2018, Oct 18. http://www.opp2.com/102749.html

4. Martin Liu. Occupation of total fans in different genders. Cucumber Media. 2018, Oct 18. http://www.opp2.com/102749.html

5. Martin Liu. Sample Characteristics of genders. 2018, Oct 18. http://www.opp2.com/102749.html

6. Martin Liu. location distribution of users. Cucumber Media. 2018, Oct 18. http://www.opp2.com/102749.html

7. Martin Liu. Location distribution of total "collected or likes". Cucumber Media. 2018, Oct 18. http://www.opp2.com/102749.html 